Shambhu Prasad Adhikari

Department of Physiotherapy

School of Medical Sciences, Kathmandu University

Nepal

ORCID iD: https://orcid.org/0000-0002-2635-6844

Jayana N. Shrestha

Department of Physiotherapy

School of Medical Sciences, Kathmandu University

Nepal

ORCID iD: https://orcid.org/0000-0001-9891-561X

Miraj Subedi

Department of Physiotherapy

Hospital for Advanced Medicine and Surgery

Nepal

ORCID iD: https://orcid.org/0000-0002-8267-7300

Address for correspondence:

Shambhu Prasad Adhikari Ph.D., PT

Department of Physiotherapy

School of Medical Sciences, Kathmandu University

Dhulikhel, Nepal

E-mail: spsaur@gmail.com

Contact number: +9779860801047

Date of submission: $2^{\text {nd }}$ November 2019

Date of acceptance: $10^{\text {th }}$ December 2019

DOI: https://doi.org:10.3126/njn.v16i3.27362

HOW TO CITE

Adhikari SP, Shrestha JN, Subedi M. Effectiveness of Kabat Rehabilitation Combined with Facial Expressive and Functional Exercises in Treatment of Bell's Palsy: A Case Study. NJNS 2019;16(3):65-67

To access Nepal Journal of Neuroscience Archives, scan $Q R$ code:

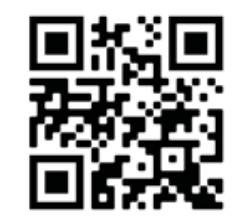

$\mathrm{L}$ ower motor facial nerve palsy also called Bell's palsy (BP) is of peripheral origin which is a common condition globally ${ }^{1}$. Physiotherapy has good evidence for better prognosis when given in early stage. The Kabat Rehabilitation (KR) has shown good outcome $^{1,2}$ in BP. The traditional facial muscle stimulation still exists as a first line treatment ${ }^{3}$. Hence, this case report was intended to shed some delights on role of KR with expressive and functional exercises.

\section{Effectiveness of Kabat Rehabilitation Combined with Facial Expressive and Functional Exercises in Treatment of Bell's Palsy: A Case Study}

Lower motor facial nerve palsy also called Bell's palsy is of peripheral origin, which is a common condition globally. Different therapeutic interventions have shown improvement in patients with Bell's palsy. Here, we administered Kabat rehabilitation combined with facial expressive and functional exercises in a patient with Bell's palsy who was treated for three weeks. Changes with the intervention were measured using Sunny-Brooke classification scoring system and House Brachmann Facial Grading scale. This case study demonstrated faster and good recovery with the combined intervention in early Bell's palsy compared to the evidence in literatures. Eyes closure was complete. Facial symmetry and well-defined facial expressions were seen after the treatment. However, clinical trials are recommended for its clinical implication.

Key words: Bell's palsy, Facial expressive and functional exercise, Kabat rehabilitation

\section{Case Report}

A 68-year-old gentleman walked into Physiotherapy Department complaining of right-sided numbness and weakness of face for the last two days. While drinking water, he noticed dripping of water from the right side of his mouth. Then he went to the mirror and saw rightsided facial drooping with inability to close the right eye. While drinking juice using a straw, air leaked out from 


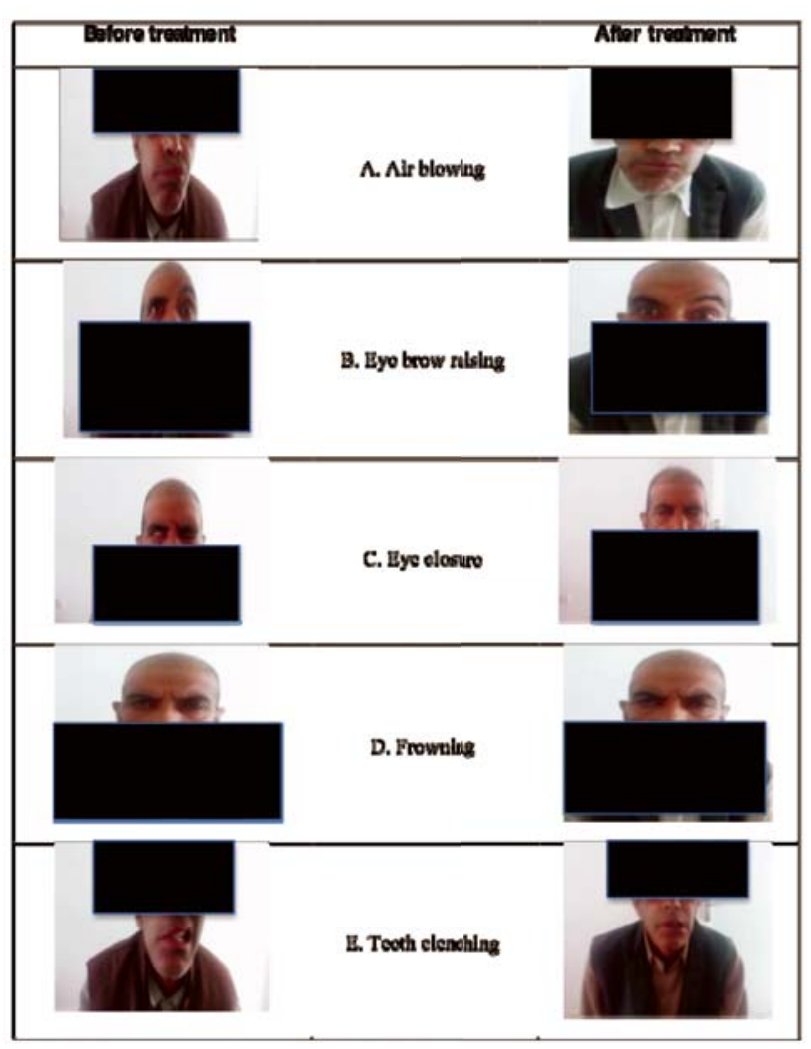

Figure 1: Facial movements before and after treatment

the straw and he had difficulty correcting it. He had no history of flu, ear infection/discharge, recent trauma, head and neck surgery or any other relevant medical or surgical conditions. He was prescribed with a drug for a few days (detail not available) on visiting a doctor.

On observation, the right eye was wide open with deviation of mouth toward left. He had difficulty in closing the right eye, dripping of water from the right angle of mouth, difficulty in blowing air from the right side of mouth and difficulty in raising eyebrows when asked to do so. A Bell's phenomenon was noticed on his right eye. We found total Sunny-Brooke classification (SBC) score of $12 / 100$. The severity was at grade V on House Brachmann Facial Grading (HBFG) scale showing complete absence of forehead movement, incomplete closure of eye and slight movement of mouth. No any facial swelling was noticed.

Physiotherapy intervention: The KR has been integrated with facial expressive and functional exercises (FEFE). KR has been effective because most muscular fibers of the facial muscles run diagonally with an easy irradiation of upper facial region due to cross VII nerve innervation ${ }^{4}$. Expressive and functional exercises can enhance KR effect ${ }^{5}$.
Physiotherapist administered Kabat Rehabilitation: Contralateral contraction and facilitation of impaired muscles was gained through irradiation, stretch, resistance and reciprocal inhibition. Muscles activation through global pattern with use of multisensory inputs: frontal, corrugator and orbicularis muscles were in vertical plane at upper fulcrum; common elevator muscles of ala nasi and upper lip muscles were in vertical line at intermediate fulcrum; risorius and orbicularis oris were in horizontal plane and mental muscle was in vertical plane in lower fulcrum.

Dose: 3-5 repetitions/muscle for 2-3 sets on each of stretch, resistance and reciprocal inhibition. Circuit training. Exercise: rest $=1: 1$, one session per day for 30 minutes, six days per week for 21 days $^{1,2,4}$. KR was followed by FEFE.

Physiotherapist-supervised facial expressive exercises: Gentle and forced eye closure-opening, raising eyebrows, forehead wrinkling, smiling, snarling and flaring nose, lips puckering/pouting, sucking cheeks between upper and lower teeth. These exercises were performed in varied amplitude and speed in front of a mirror. Involuntary movements were avoided and circuit training was done with equal rest period. Dose: 5-10 repetitions/exercise for 21 days. Patient was also advised for facial expressive exercises at home 2 times a day exactly in the way trained by the physiotherapist ${ }^{5,6}$.

Home-based functional exercises: Air blowing in balloons, blowing the straw from right side of mouth, sucking water using straw, making "fff" and vowel sounds, blowing papers (varied thickness in progression), 5 repetitions/task, 3-4 times a day, for 21 days $^{5,6}$.

Post treatment findings: As shown in figure 1, there were significant observational differences in various facial movements before and after treatment.

As displayed in figure 2, the SBC score at the end of the session increased from $12 / 100$ to $68 / 100$. The HBFG scale demonstrated improvement from grade $\mathrm{V}$ to grade I. On first and second week of treatment, the recovery was faster compared to third week.

\section{Discussion}

This case study demonstrated faster and good recovery with KR integrated with FEFE in early BP with respect to the evidence in existing literatures. Eyes closure was complete. Facial symmetry and well-defined facial expressions were seen after the treatment.

Therapist administered KR produced significant improvement in eyes closure and symmetry of the face within three weeks, which is a good indicator of KR with FEFE. Simonetta et al demonstrated speedy recovery 


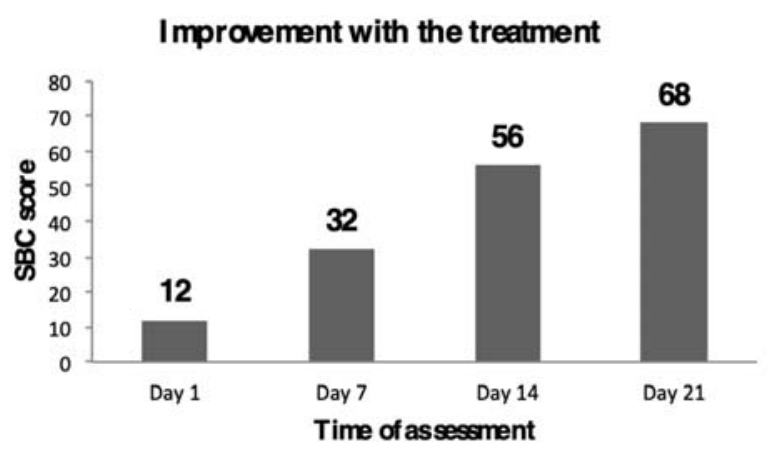

Figure 2: Improvement in Sunny-Brooke classification (SBC) score

showing two-HB grade improvement with KR compared to the control group ${ }^{1}$. Our participant demonstrated fourHB grade improvement, which is in line, but much more improvement than that shown in the study by Simonetta et $\mathrm{al}^{1}$. Simonetta et al in another study ${ }^{2}$ and Barbara et $\mathrm{al}^{4}$ demonstrated speedy recovery with KR in large number of participants of different age and varied severity grades which is consistent with our findings. Peitersen et $\mathrm{al}^{7}$ described BP recovery within six months without medical and physiotherapy treatment. Being a self-relieving condition, it might be true but the recovery was too slow which might yield residual impairments, which was not specified. Different interventions like transcutaneous electrical stimulation ${ }^{3}$, massage ${ }^{8}$ facial muscle stimulation and exercises ${ }^{6}$ have shown better therapeutic effect. However, there were argument regarding recovery speed.

Early and better improvement seen with the combination of $\mathrm{KR}$ and FEFE in present case was supported by the evidence of recovery in 15 days following $\mathrm{KR}^{4}$ and in 3-5 months following FEFE 9 . Though speedy recovery occurs at the beginning of the treatment, treatment is to be continued up to three months for complete recovery and/ or reduce reoccurrence.

There was improvement in impairment such as eyes closure, brow raising, brow frowning, air blowing and clenching beside gross improvement similar to the findings in a study by Beurskens et $\mathrm{al}^{9}$. However, the impairment to improve first could not be detected.

The sequence of interventions was supported with motor control, learning and neuroscience principles ${ }^{10}$. There may be reinforcement of one intervention effect by another. Additionally, a clear role of physiotherapists was indicated to administer KR at the clinic and a need of well-planned home prescription was highlighted.

\section{Conclusions}

Therapist-administered KR integrated with FEFE demonstrated effective, speedy and significant recovery in early BP while comparing with the evidence in existing literatures. However, clinical trials with control groups are further recommended for its clinical implication.

Patient consent: Written informed consent was taken from the participant prior to examination and treatment.

Conflicts of interest: None of the authors have potential conflicts of interest to be disclosed.

\section{References}

1. Monini S, Buffoni A, Romeo M, Di Traglia M, Filippi C, Atturo F, et al. Kabat rehabilitation for Bell's palsy in the elderly. Acta Otolaryngol. 2017;137(6):64650. DOI: 10.1080/00016489.2016.1262553

2. Monini S, Iacolucci CM, Di Traglia M, Lazzarino AI, Barbara M. Role of Kabat rehabilitation in facial nerve palsy: a randomised study on severe cases of Bell's palsy. Acta Otorhinolaryngol Ital. 2016;36(4):282-8.

3. Shrestha A, Sharma M. Efficacy of Transcutaneous Electrical Nerve Stimulation (TENS) in the Treatment of Bell's Palsy. NJNS. 2011 Dec;8(2):147-9. DOI: 10.3126/njn.v8i2.22768

4. Barbara M, Antonini G, Vestri A, Volpini L, Monini S. Role of Kabat physical rehabilitation in Bell's palsy: a randomized trial. Acta Otolaryngol. 2010;130(1):167-72. DOI: 10.3109/00016480902882469

5. Aranha VP, Samuel AJ, Narkeesh K. Correct the smile of a child by neuromuscular facilitation technique: An interesting case report. Int $\mathbf{J}$ Health Sci (Qassim). 2017;11(2):83-4.

6. Pereira LM, Obara K, Dias JM, Menacho MO, Lavado EL, Cardoso JR. Facial exercise therapy for facial palsy: systematic review and metaanalysis. Clin Rehabil. 2011;25(7):649-58. DOI: 10.1177/0269215510395634

7. Peitersen E. Bell's palsy: the spontaneous course of 2,500 peripheral facial nerve palsies of different etiologies. Acta Otolaryngol Suppl. 2002;(549):430. DOI: $10.1080 / 000164802760370736$

8. Beurskens CH, Heymans PG. Mime therapy improves facial symmetry in people with long-term facial nerve paresis: a randomised controlled trial. Aust J Physiother. 2006;52(3):177-83. DOI: 10.1016/ S0004-9514(06)70026-5

9. Beurskens $\mathrm{CH}$, Heymans PG. Physiotherapy in patients with facial nerve paresis: description of outcomes. Am J Otolaryngol. 2004;25(6):394-400. DOI: $10.1016 /$ j.amjoto.2004.04.010

10. Kandel ER, Schwartz JH, Jessell TM. Principles of Neural Science. 4th ed. 2000. 